\title{
The Effect of Simulated Transportation Conditions on the Chemical, Physical and Sensory Profiles of Müller-Thurgau and Scheurebe Wines
}

\author{
Molly Crandles, Martha Wicks-Müller, Christoph Schuessler and Rainer Jung \\ Hochschule Geisenheim University, Von-Lade-Strasse 1, D-65366, Geisenheim, Germany
}

\begin{abstract}
The impact of different phases of shipment (at sea and at port) on two German white wines of two vintages and the lasting effects of the temperature regimes over time was investigated. The wines were subjected to three temperature programs-control $\left(15{ }^{\circ} \mathrm{C}\right)$, linear increase $\left(15^{\circ} \mathrm{C}\right.$ steadily increasing to $\left.45{ }^{\circ} \mathrm{C}\right)$, and diurnal fluctuation $\left(15^{\circ} \mathrm{C} / 40{ }^{\circ} \mathrm{C}\right)$-in both movement and non-movement conditions. The wines were analyzed for chemical, physical and sensorial changes at one and eight months post-treatment. Changes in temperature and pressure were recorded within the bottles, which correlated with the temperature programs: $+0.04 \mathrm{bar} /{ }^{\circ} \mathrm{C}$ in the linear increase program and $+0.08 \mathrm{bar} /{ }^{\circ} \mathrm{C}$ in the diurnal fluctuation program. The oxygen levels in the headspace and in the wine were monitored during all of the treatments. The oxygen development in the bottles was similar between the diurnal and linear programs, and was found to be distinctive from the control program. The chemical analysis revealed that there were significant differences related to the experimental treatments of the wines for the following parameters: tartaric acid, free sulfur dioxide, total sulfur dioxide and percent cork weight loss measurements. Difference sensory testing found very few differences. After eight months storage, significant differences were found in the Diurnal Non-movement treatment compared to Linear Non-movement and control treatments, as well as Diurnal Movement and Control treatments for the 2014 Müller-Thurgau wine. Sensory descriptive analysis of the wines found that the wines could be differentiated by variety, but could not be distinguished according to experimental treatment after one month storage. These results indicate that wines of these types are more robust to shipping conditions than previously found.
\end{abstract}

Key words: Simulated transportation conditions, Scheurebe, Müller-Thurgau, oxygen, descriptive analysis.

\section{Introduction}

There are numerous stages of the enological process which have an impact on a wine's characteristics and overall quality. After bottling, several factors influence the wine quality including light exposure, humidity, oxygen, vibrations, temperature, $\mathrm{pH}$, acidity and overall wine matrix [1]. The shelf life of a wine essentially begins at bottling, and from this moment the product is subject to quality deterioration [2]. The conditions that wine is subjected to during shipment can play a role in the loss of wine quality due to temperature changes, bottle movement and associated oxygen uptake. Wines can suffer from several chemical, organoleptic and physical defects when

Corresponding author: Martha Wicks-Müller, M.Sc., research field: wine sensory science. exposed to poor shipping situations, including the development of maderized and oxidized notes, reduction of fruit notes, reduction of carbon dioxide, colour changes, raised corks, leakage and even broken packaging [3].

It is not uncommon for wines to be submitted to extreme temperatures (above $45{ }^{\circ} \mathrm{C}$ ), often with significant fluctuations, when they are transported [3, 4]. Wines that are transported between continents may be subjected to a variety of temperature patterns in a shipping container, including a steady increase of temperature affecting wines shipped from winter temperatures towards the equator and further on to summer temperatures [4]. Perhaps the most extreme shipping temperatures are experienced during the transshipment phase, since relay ports are often 
located close to the equator. While the wine is sitting in the transshipment phase, it is generally unprotected and therefore is subject to extreme differences between night and day temperatures-“diurnal fluctuations" [4]. Another study showed that in wine transportation across the USA, there can be temperature fluctuations of up to $21^{\circ} \mathrm{C}$ in one day [5]. This has a significant impact on the wine quality, due to the expansion and contraction of the wine volume at these fluctuating temperatures. The thermal expansion of wine between $20^{\circ} \mathrm{C}$ and $40{ }^{\circ} \mathrm{C}$ is up to $0.8 \%$ of the volume, or $0.3 \mathrm{~mL}$ for each Celsius degree in extreme cases such as wines with high residual sugar. The repeated expansion and contraction of a wine subjected to diurnal fluctuations can cause significant changes to the wine, since air will be expelled from the bottle as the wine warms, possibly to the point of cork movement, and then air will be drawn into the bottle as the wine cools, especially if the cork seal is compromised. This can result in an increased risk of oxidation of the wine, as well as a change in vapour pressure and carbon dioxide solubility [4]. It has also been shown that transportation can have an influence on wine quality due to movement: shipment in trucks cause vibrational frequencies between 2-5 Hz (120-300 rpm), which can cause significant damage to fragile products [6]. Vibrations can affect the wine's sensory attributes, because there is an impact on the sedimentation and the biochemical evolution [7]. It was shown that wines at higher vibration levels had lower propanol and isoamyl alcohol content, which indicates that minimizing the movement of a wine assists in retaining higher alcohols and overall wine aroma [7]. Another study [8] indicated that storage time and temperature are more important for oxygen permeation than mechanical movement.

A study on the impact of shipping wines across the USA showed that transportation can cause a bottle aging effect on wine of between 1 to 18 months when compared to wine stored at cellar temperatures [5].
Wines submitted to high temperatures and fluctuating temperatures have been shown to be more sensorially impacted than wines kept at $0{ }^{\circ} \mathrm{C}$ or less [9]. The impact of shipping on the wine parameters varied with the temperature program and length of shipping period, but also depended on the wine matrix. It has been shown that the impact of transportation at higher temperatures was not detectable by a sensory panel for red wines, but the differences were more prominent for white wines [4]. Several common wine varieties were studied under various shipping and storage conditions: storage at $20^{\circ} \mathrm{C}, 40{ }^{\circ} \mathrm{C}$, a diurnal cycle between $20^{\circ} \mathrm{C}$ and $40{ }^{\circ} \mathrm{C}$, and a sample traveling in a car trunk in winter time [11]. Wines stored at higher temperatures were found to be significantly different from those stored at cellar conditions in terms of aroma profile. Specifically, tropical fruit and apple aromas were negatively correlated with rubber and diesel aromas according to the sensory analysis. For the wines stored at higher temperatures, reductions in esters and acetates occurred, as was expected as increased temperature expedited the aging process [11]. Wines in the higher temperature programs had aromas in the diesel, oxidized and rubber aromas, while wines at lower temperatures maintained their citrus, floral and tropical fruit aromas [11].

This experiment was intended to investigate the impact of shipping conditions on two dry, white wines of different vintages. The impact of linearly increasing temperatures, such as those experienced during transport at sea, and diurnally fluctuating temperatures, such as those experienced while sitting at port, was investigated alongside the impact of movement of the bottles in comparison to typical cellar conditions: $15^{\circ} \mathrm{C}$ without physical movement.

\section{Materials and Methods}

This experiment was performed on two white wines, both in bottle with natural cork closures: 2013 Weinheimer Sybillenstein Scheurebe Trocken (Rheinhessen) and 2014 Nussdorfer Herrenberg 
Müller-Thurgau Trocken (Pfalz). These wines were subjected to three different temperature treatments: a constant cellar temperature $\left(15^{\circ} \mathrm{C}\right)$, a linear increase in temperature $\left(15{ }^{\circ} \mathrm{C}\right.$ to $45^{\circ} \mathrm{C}$ over a 6 day period), and a diurnal fluctuation of temperature (between $15^{\circ} \mathrm{C}$ and $40^{\circ} \mathrm{C}$ over 12 hours for 8 days), carried out in a Memmert ICH 750 (Model UF 750, Memmert GmbH + Co.KG, Schwabach, Germany) programmable temperature chamber. The temperature programs were designed to have equal amounts of thermal energy applied. Within each temperature program, there were some bottles which were held still and other bottles which were subjected to mechanical movement. The movement bottles were shaken for a total of 5 hours on a dual action shaker table (Model KL-2, Edmund Bühler GmbH, Hechingen, Germany) moving at $125 \mathrm{rpm}$. In total, there were six treatments applied to each variety: Control-Non-Movement (CNM), Control-Movement (CM), Linear-Non-Movement (LNM), Linear-Movement (LM), Diurnal-Non-Movement (DNM), and Diurnal-Movement (DM). STAR:0DDI submersible thermometer/ pressure readers (DST Milli-T, STAR:0DDI, Gardabaer, Iceland), or "data loggers", were used to record actual temperatures within 12 randomly selected bottles within each temperature program. Temperature and pressure readings were recorded every thirty minutes.

\subsection{Oxygen Measurements}

In-bottle oxygen levels in the headspace and wine were monitored using non-invasive oxygen sensor spots alongside a fiber optic oxygen meter (Fibox 3-Trace, PreSens GmbH, Regensburg, Germany). The Pst3 oxygen sensor spots (linearity range $0-50 \%$ oxygen, PreSens) were fixed to the inside of clear glass bottles with silicon glue (RS Components, Morfelden-Walldorf, Germany), taking care to avoid air bubbles. In total, 8 bottles were used for oxygen analysis, and each of these bottles had a sensor spot in both the headspace and in the wine; one sensor was placed $5 \mathrm{~cm}$ below the top lip to measure the headspace oxygen between the wine and the cork, and the other sensor was placed $12 \mathrm{~cm}$ from the bottom to measure the oxygen levels in the wine. Each variant was measured in duplicate for oxygen evolution.

The dissolved oxygen and headspace oxygen measurements in the wine and headspace were taken with the PreSens Oxygen Analyzer every day at noon. Oxygen bottles which were subjected to mechanical movement had recordings taken before and after the shaking period.

\subsection{Chemical and Physical Analysis}

After the wines were submitted to the simulated transportation temperatures, they were compared to the wines kept at standard cellar conditions $\left(15^{\circ} \mathrm{C}\right)$. Three wines from each treatment were sampled and analyzed by a Fourier Transform InfraRed (FTIR) Foss Machine. This analysis was performed by the Geisenheim Enology Lab according to standard procedures, and included measurements for $\mathrm{pH}$, total acidity, alcohol, density, sugars and acids. Measurements of free and total sulfur dioxide $\left(\mathrm{SO}_{2}\right)$ were performed in triplicate for each treatment. The measurements were carried out using the flow injection analysis technique using a Foss FIAstar 5000 Analyzer (Rellingen, Germany). Samples from each treatment were analysed for color at $420 \mathrm{~nm}$ using a DR Lange CADAS 200 Spectral Photometer (Hach Lange GmbH, Dusseldorf, Germany, $1 \mathrm{~cm}$ cuvette). ASTM software (Standards on Color and Appearance Measurement, West Conshohocken, USA) was used to calculate the CIELab parameters $\mathrm{L}^{*}, \mathrm{a}^{*}$ and $\mathrm{b}^{*}$. When the corks were removed from the bottles which were sampled for FTIR, $\mathrm{SO}_{2}$ and colour analysis, they were immediately weighed. Then, the corks were dried in a drying oven (Ehret TK/L 4105, EHRET $\mathrm{GmbH}$ und Co.KG, Emmendingen, Germany) at $80{ }^{\circ} \mathrm{C}$ for 24 hours in order to determine the dry weight and cork moisture. 


\subsection{Sensory Analysis}

The wine treatments were compared sensorially one month after treatments using Triangle Tests with a panel of 13 to 14 expert judges and again after eight months with a panel of 11 to 14 expert judges. Wines were presented in a randomized order using three digit codes. The triangle test sheets were prepared using FIZZ software (version 4.46A, Biosystemes, Couternon, France).

A panel of 13 judges was trained to carry out a descriptive analysis of the wines as described by Lawless and Heymann [12]. The panel consisted of 4 females and 9 males of 10 different nationalities, ranging in age from 19 to 42 years old. The training occurred over 7 sessions and the descriptive analysis was carried out over 6 sessions. The list of aroma and mouthfeel standards and their preparations can be seen in Table 1.

The judges were further trained through testing their ability to blindly identify the aroma standards by name. Different concentrations of the aroma standards were prepared in the following manner: the aroma standards prepared according to Table 1 were set as the high concentration; the medium concentration aroma standards were prepared using $20 \mathrm{~mL}$ of the high concentration standard and $10 \mathrm{~mL}$ wine; the low concentration standards were prepared using $10 \mathrm{~mL}$ of the high concentration standard and $20 \mathrm{~mL}$ of wine. These different concentrations were presented blindly to the panelists for each attribute, and the panelists were asked to rank the samples according to concentration. The judges were also tested on their ability to identify mouthfeel standards (acidity, sweetness, bitterness), and the same ranking tests were performed to identify different concentrations of these mouthfeel standards (prepared in the same manner as the aroma standards).

After the training sessions, the descriptive analysis of the 6 treatments for the 2 varieties in triplicate (36 samples total) was carried out. All attributes were rated on a $9 \mathrm{~cm}$ line scale marked with a 0 at the left end and a 9 at the right end. The wines were served at $15 \pm 1{ }^{\circ} \mathrm{C}$ in ISO standard wine glasses (Schott Zwiesel, Zwiesel, Germany) and were tasted within less than 1 hour of pouring. The descriptive analysis sheets were prepared using FIZZ software (version 4.46A, Biosystemes, Couternon, France).

\subsection{Statistical Analysis}

All statistical analyses for the one month chemical and physical results were performed using R: A Language and Environment for Statistical Computing,

Table 1 Sensory standards for descriptive analysis training.

\begin{tabular}{|c|c|}
\hline Sensory standard & Preparation \\
\hline Citrus fruit & $\begin{array}{l}75 \mathrm{~mL} \text { wine, infused with } 7 \text { pieces }\left(1 \mathrm{~cm}^{3}\right) \text { fresh grapefruit (with skin), } 7 \text { pieces }\left(1 \mathrm{~cm}^{*} 1 \mathrm{~cm}^{*} 1 \mathrm{~mm}\right) \text { fresh } \\
\text { lemon zest for } 1 \text { hour. }\end{array}$ \\
\hline Burnt aroma & $1 \mathrm{~cm}$ piece of elastic band, burnt and 1 match, struck. \\
\hline Tropical fruit & $\begin{array}{l}75 \mathrm{~mL} \text { wine, infused with } 5 \text { pieces }(1 \mathrm{~cm} * 1 \mathrm{~cm} * 10 \mathrm{~mm}) \text { fresh banana, } 5 \text { pieces }(1 \mathrm{~cm} * 1 \mathrm{~cm} * 1 \mathrm{~mm}) \text { canned } \\
\text { lychee, } 10 \mathrm{~mL} \text { pineapple juice for } 1 \text { hour. }\end{array}$ \\
\hline Vegetable & $\begin{array}{l}75 \mathrm{~mL} \text { wine, infused with } 4 \text { pieces }\left(1 \mathrm{~cm} * 1 \mathrm{~cm}^{*} 10 \mathrm{~mm}\right) \text { fresh cucumber, } 4 \text { pieces }\left(1 \mathrm{~cm}^{*} 1 \mathrm{~cm}^{*} 1 \mathrm{~mm}\right) \text { fresh } \\
\text { asparagus, } 5 \text { pieces }(1 \mathrm{~cm} * 1 \mathrm{~cm} * 1 \mathrm{~cm}) \text { fresh rhubarb for } 1 \text { hour. }\end{array}$ \\
\hline Candy aroma & $75 \mathrm{~mL}$ wine infused with 4 gummy bears (mini, Haribo, assorted flavours) and $1 / 2$ ice bon candy for 1 hour. \\
\hline Stone fruit & $75 \mathrm{~mL}$ wine infused with 1 Apricot-Tea bag (Meßmer, Aprikose-PfirsichLiblich-Mild) for 1 hour. \\
\hline Oxidized aroma & 75 mL 2008 Rheingau Riesling wine left open for 2 months. \\
\hline Earthy/Moldy & $75 \mathrm{~mL}$ wine infused with $10 \mathrm{~g}$ soil for 1 hour. \\
\hline Honey/Marzipan & $\begin{array}{l}75 \mathrm{~mL} \text { wine infused with } 1 \text { tbsp honey (LangneseSommerblüteHonig), } 0.05 \mathrm{~g} \text { almond aroma powder (Dragoco } \\
\text { Mandel Seuss Aroma Spruegetrocknet } 0.1 \% \text { Fondant) for } 1 \text { hour }\end{array}$ \\
\hline Acidity & $250 \mathrm{~mL}$ water with $0.5 \mathrm{~g}$ citric acid (Merck, powder, CAS 77-92-9). \\
\hline Sweetness & $250 \mathrm{~mL}$ water with $5 \mathrm{~g}$ sucrose (Merck, powder, CAS 57-50-1). \\
\hline Bitterness & 250 mL water with 0.2 g caffeine (Merck, powder, CAS 58-08-2). \\
\hline
\end{tabular}


Version 3.0.1. with Agricolae Package (R Core Team 2013). The statistical analyses for the sensory results were performed using FIZZ software (version 4.46A, Biosystemes, Couternon, France). For the eight month data, $\mathrm{R}$ and XLSTAT were used.

\section{Results}

The results of the temperature and pressure measurements are presented in Figs. 1-4 as averages for each of the simulated transportation programs. Two data loggers were found to be measuring below the range of pressure specified by the manufacturer and therefore were removed from the average results. The results of the data logging indicated that all of the temperature programs were carried out according to the planned programs (Fig. 1). In the Linear program, in spite of efforts to reduce the loss of heat, there were daily decreases in temperature and pressure when the bottles were removed from the cabinet for shaking and replaced afterwards. These drops in pressure and temperature became more dramatic as the program reached higher temperatures. This issue was avoided in the Diurnal and Constant programs. In all three of the programs, movement of the bottles displayed varying impact on the pressure. It was consistently observed that the temperature was the most significant factor that impacted the pressure within the bottles. In the Linear program, an increase of pressure of 0.04 bar was observed for every increased degree Celsius of temperature. The Diurnal program created a higher rate of pressure increase, with the pressure increase 0.08 bar per ${ }^{\circ} \mathrm{C}$. Figs. 2-4 display the pressure averages for the two wines over the three temperature programs. The pressures for the Scheurebe wines in general were higher than for the Müller-Thurgau wines, particularly for the Linear heat program. This is likely due to the expulsion of corks experienced by the Müller-Thurgau wines early on in the diurnal program and late in the linear program. In Fig. 3, it can be seen that after day 4, there is a marked difference between the two Müller-Thurgau variants and the Scheurebe wines. The Scheurebe wines continue to follow an increasing trend in pressure and eventually overlap, suggesting that at this point in the program, the thermal expansion of the wines due to heat plays a larger role in pressure; whereas the Müller-Thurgau wines show a leveling out or even decrease in pressure and a distinct separation of the LM and LNM variants.

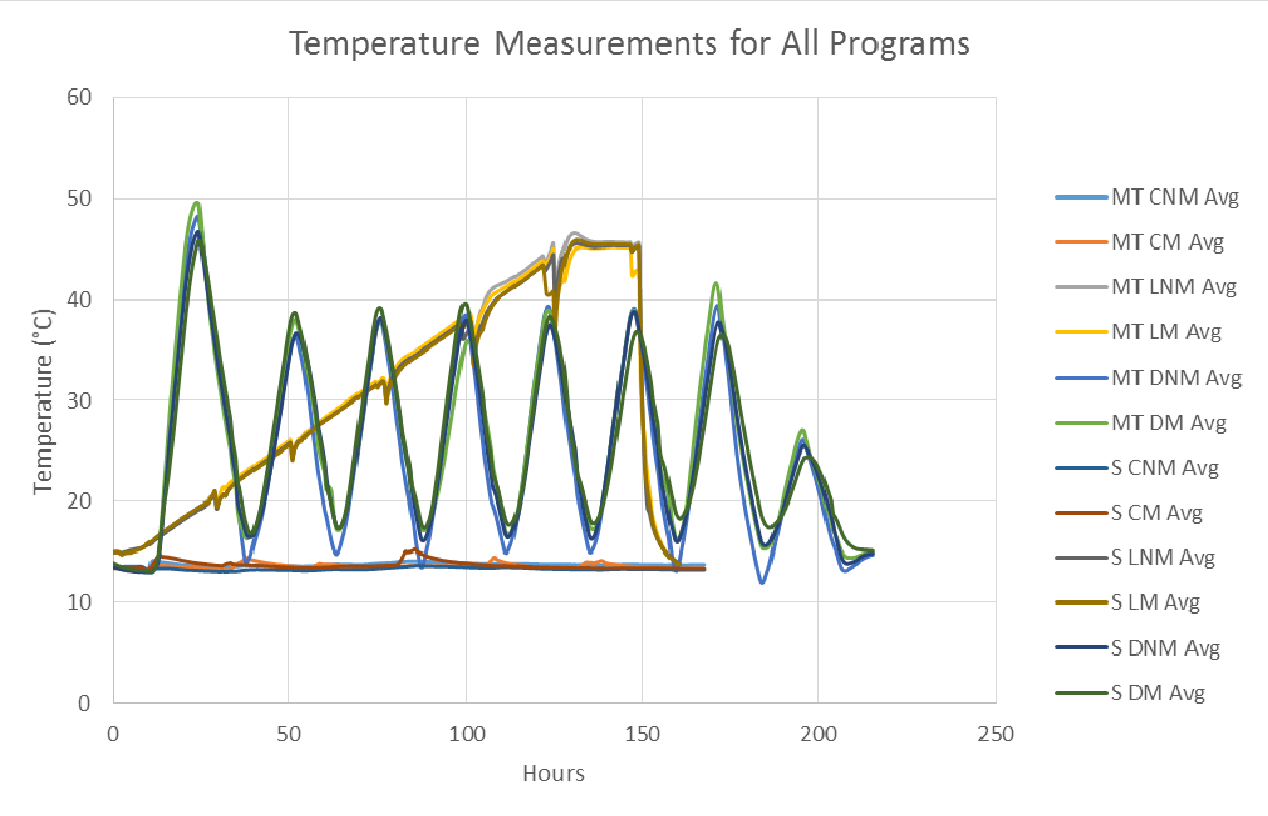

Fig. 1 Average temperature recordings for all programs. 

Sensory Profiles of Müller-Thurgau and Scheurebe Wines

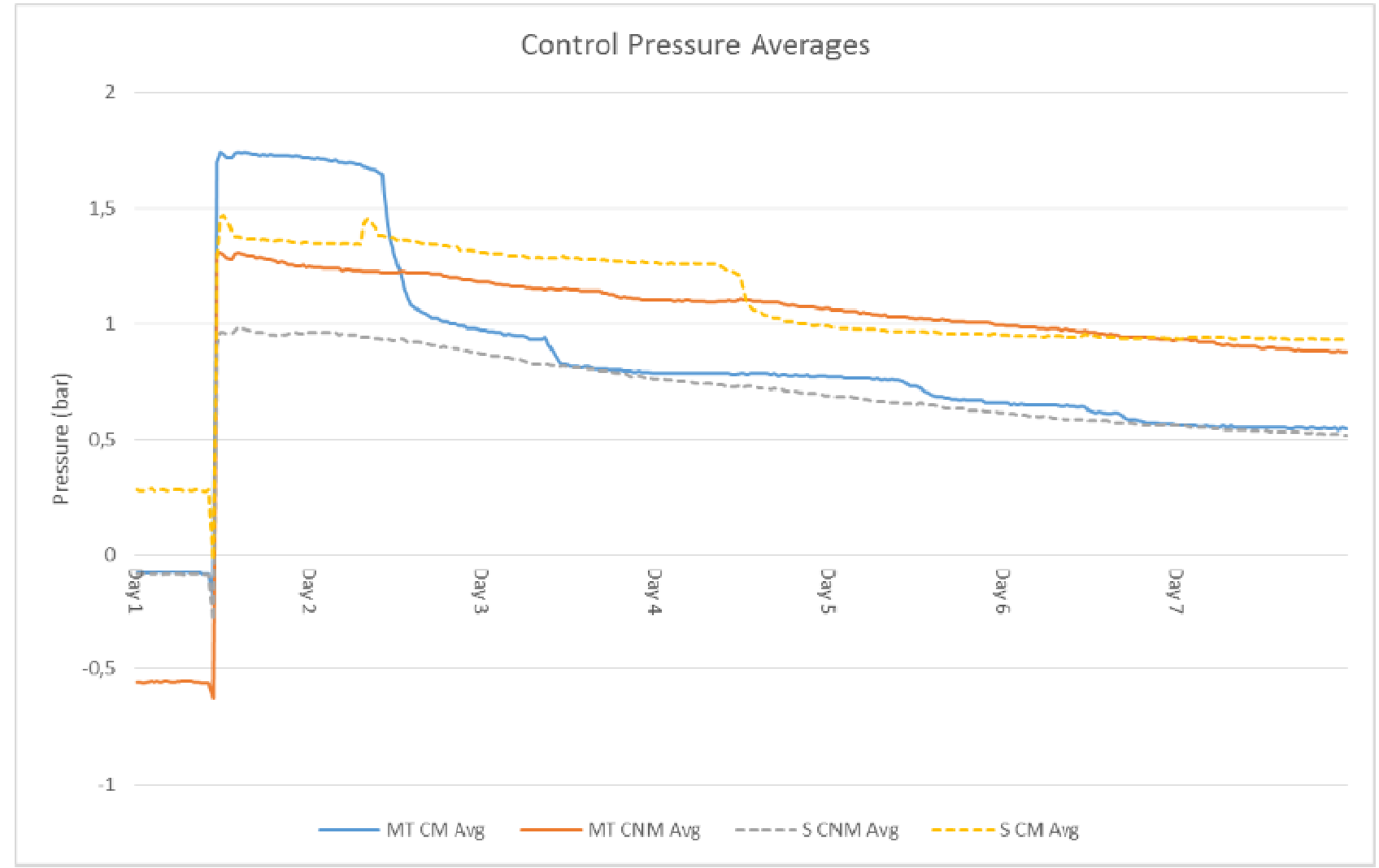

Fig. 2 Average pressure measurements for control programs.

Linear Heat Program Pressure Averages

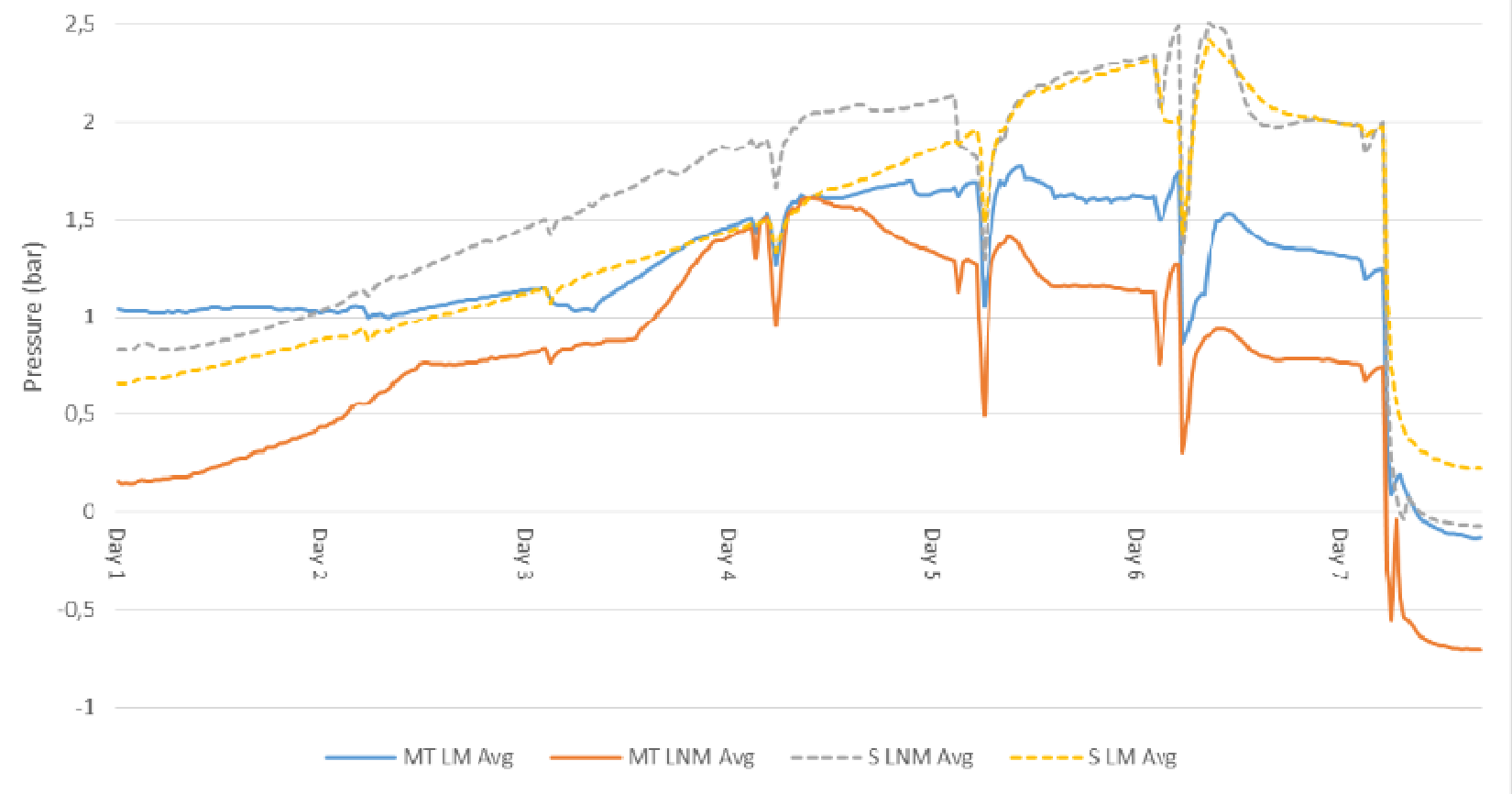

Fig. 3 Average pressure measurements for linear programs. 


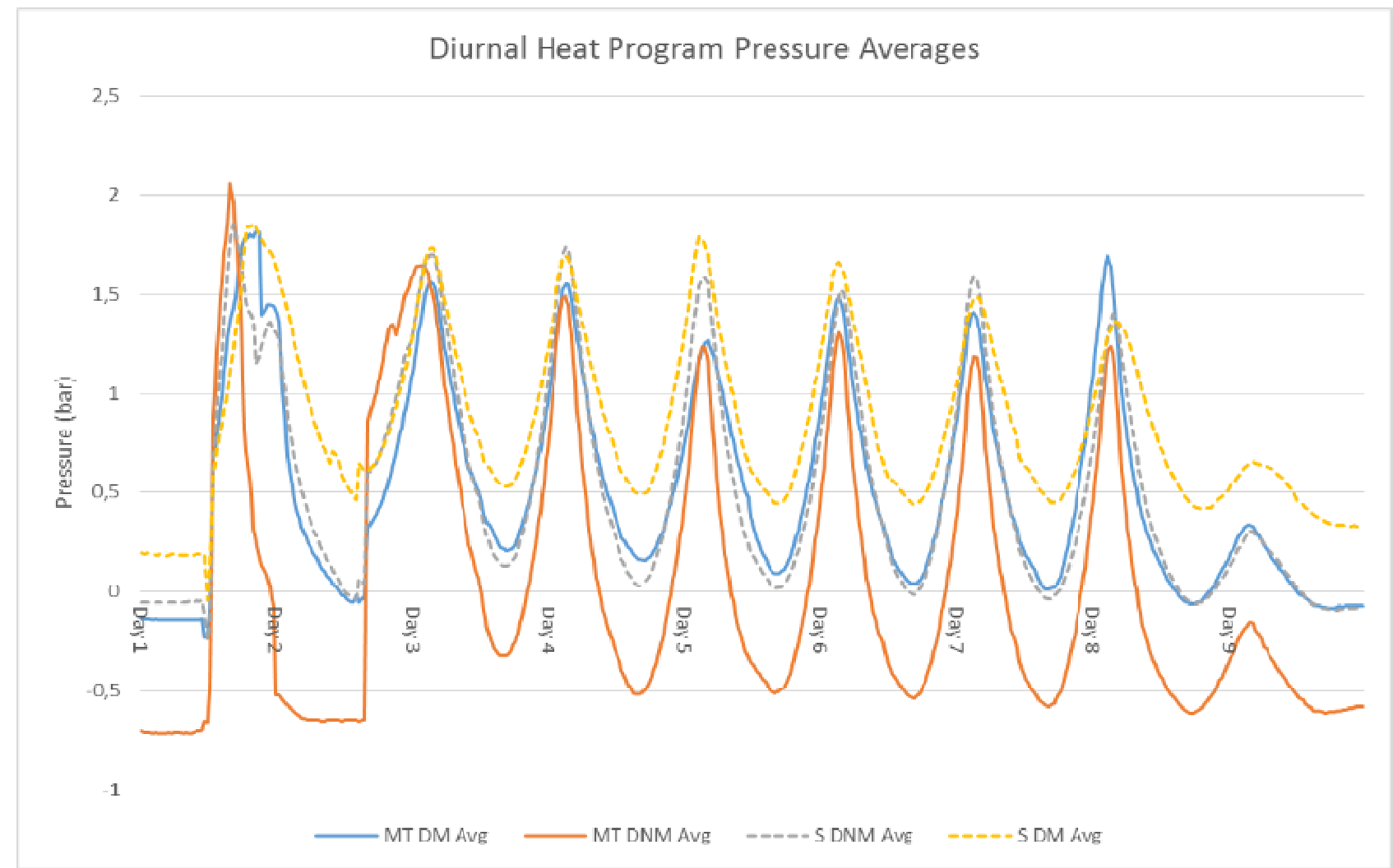

Fig. 4 Average pressure measurements for diurnal programs.

With the expulsion of the corks, the pressure from gas in the bottle is released. As the temperature program continues, the vibrated bottles show a greater pressure than those left in the temperature cabinet.

In the diurnal program (Fig. 4), movement of the wines also appeared to have an effect on the pressure of bottles. In both the Scheurebe and the Müller-Thurgau, the movement bottles measured higher pressures in the cooler periods. The behavior of the Scheurebe wines mirror the Müller-Thurgau, however with higher pressures. As in the later part of the linear program, cork expulsion was experienced with the Müller-Thurgau wines in the beginning of the diurnal program. To prevent this from continuing to occur, the program was rewritten with a lower maximum temperature. With the shaking of the wine, it is likely that the gases in the headspace were being moved into the wine in an accelerated manner. Since the solubility of gases into liquid is temperature dependent and better soluble in cooler temperatures, this could explain why the shaking seems to have had an impact on the pressure in the movement bottles for the diurnal program. The movement of the bottles were all timed such that as the temperature program was nearing $15{ }^{\circ} \mathrm{C}$, the bottles were shaken, as to not loose thermal energy.

Fig. 5 presents the oxygen measurements taken in bottles from each program in both the headspace of the bottle and within the wine. It was seen in the Control Non-Movement program that wines which were not exposed to increased temperature or movement showed a steadily decreasing level of oxygen in the headspace. This trend was accompanied by a corresponding increase in the oxygen level in the wine. In the Control Movement program, it was observed that the movement of the wine caused a faster uptake of oxygen in the wine from the headspace. There were higher final levels of oxygen within the wines in the CM program than the CNM program which can be attributed to the movement of the bottles causing an increased rate of oxygen uptake in the wine. In both the Linear and Diurnal programs, it 

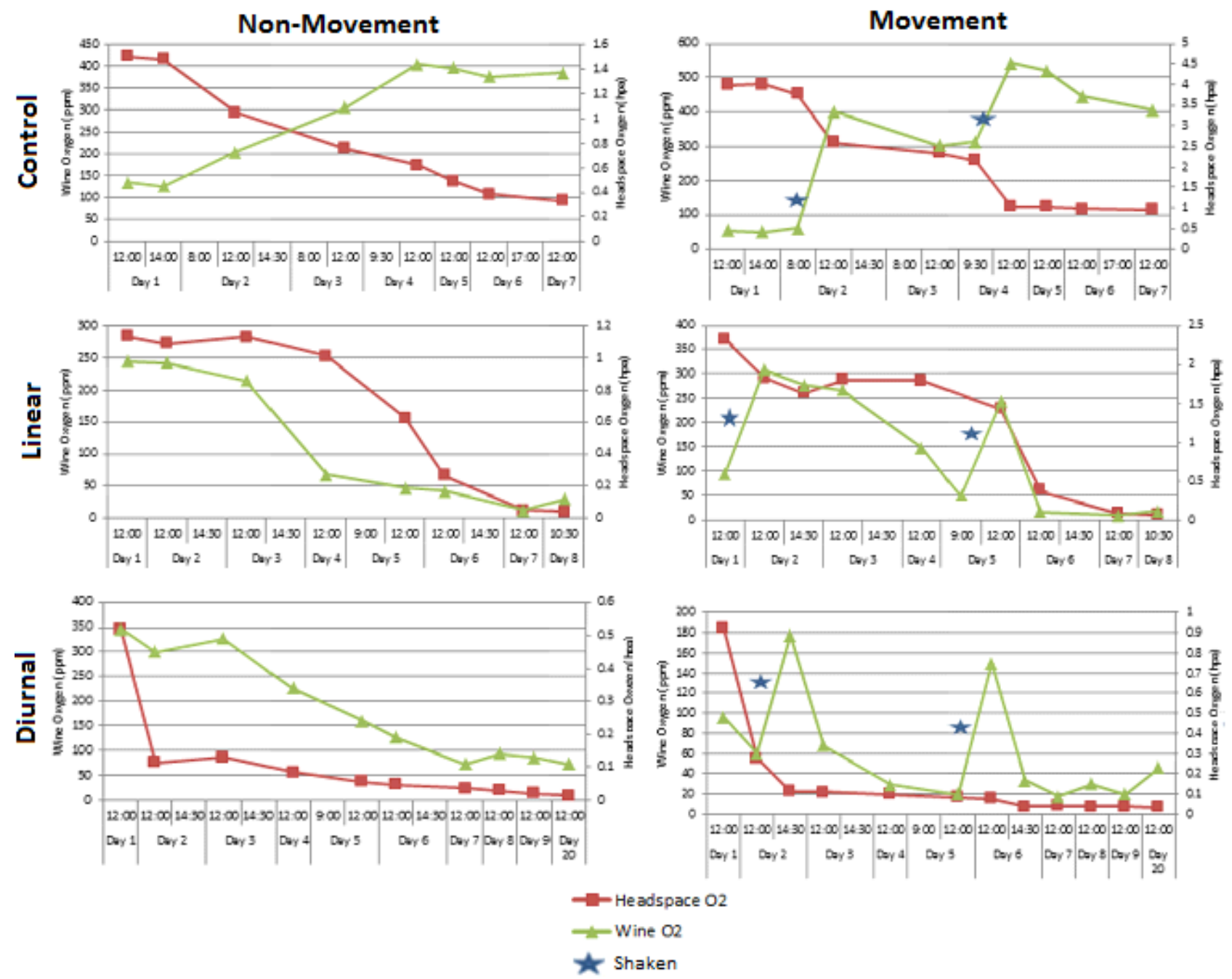

Fig. 5 Oxygen measurements throughout transportation programs.

was observed that there was a decrease in oxygen in the wine as the temperature increased. The trend of increased oxygen uptake in the wine when the bottles were subjected to movement was reinforced in both the LM and DM programs.

The chemical and physical analyses examined several parameters of the wines which are shown in Table 2. Table 2 reveals that there was a statistically significant difference between the Scheurebe and Müller-Thurgau wines related to density, alcohol, extracts, sugars, total acidity, specific acids, glycerin and sulfur dioxide levels, according to the Analysis of Variance performed on the measurements. These differences can be attributed to the differing composition of the grape varieties before the enological process. The ANOVA also revealed that the individual temperature and movement treatments had a statistically significant impact on the tartaric acid, free sulfur dioxide, total sulfur dioxide and percent cork weight loss measurements. After one month of storage, post-hoc analysis revealed differences in free sulfur among the samples was limited to the LNM variant, however after eight months storage, the free sulfur measurements showed significant differences among the Müller-Thurgau wines. Previously, differences in sulfur dioxide (free and total) were analyzed to determine if there were significant differences between wines which experienced cork expulsion and those which did not. No significant differences were detected after the one 
Table 2 Statistical analysis of chemical results: 3-way anova with interactions.

\begin{tabular}{|c|c|c|c|c|c|c|}
\hline Parameter & Variety & Treatment & Replicate & $\begin{array}{l}\text { Variety: } \\
\text { treatment }\end{array}$ & $\begin{array}{l}\text { Variety: } \\
\text { replicate }\end{array}$ & $\begin{array}{l}\text { Treatment: } \\
\text { replicate }\end{array}$ \\
\hline Density & $3.05 \times 10^{-14} * * *$ & 0.0656 & 0.3594 & $\begin{array}{l}0.0279 \\
*\end{array}$ & 0.8715 & 0.4485 \\
\hline Alcohol & $2.93 \times 10^{-14} * * *$ & 0.1686 & 0.7077 & 0.1735 & 0.534 & 0.4217 \\
\hline Extract & $6.60 \times 10^{-6} * * *$ & 0.0716 & 0.6257 & 0.1583 & 0.8522 & 0.3309 \\
\hline Sugar free extract & $6.11 \times 10^{-7} * * *$ & 0.0559 & 0.6518 & 0.1584 & 0.8220 & 0.2938 \\
\hline Residual sugar & $2.49 \times 10^{-6} * * *$ & 0.2013 & 0.4619 & 0.0595 & 0.9236 & 0.4001 \\
\hline Glucose & $0.00366 * *$ & 0.3856 & 0.5828 & 0.3320 & 1.0000 & 0.4893 \\
\hline Fructose & $9.54 \times 10^{-10} * * *$ & 0.5084 & 0.6039 & 0.7146 & 0.7043 & 0.9660 \\
\hline Total acidity & $1.03 \times 10^{-10} * * *$ & 0.1690 & 0.6552 & 0.2570 & 0.8651 & 0.5000 \\
\hline $\mathrm{pH}$ & 0.3331 & 0.1105 & 0.3905 & 0.1343 & 0.7164 & 0.3537 \\
\hline Tartaric acid & 0.4295 & $\begin{array}{l}0.0445 \\
*\end{array}$ & 0.5750 & 0.18085 & 0.7886 & 0.2433 \\
\hline Citric acid & $1.15 \times 10^{-11} * * *$ & 0.1535 & 0.6327 & 0.1710 & 0.9342 & 0.7094 \\
\hline Malic acid & $2.30 \times 10^{-11} * * *$ & 0.4651 & 0.2121 & 0.4651 & 0.2121 & 0.5000 \\
\hline Volatile acidity & $1.28 \times 10^{-5} * * *$ & 0.5101 & 0.5417 & 0.3520 & 0.2649 & 0.4024 \\
\hline Glycerin & $1.89 \times 10^{-5} * * *$ & 0.0671 & 0.6693 & 0.0771 & 0.9834 & 0.2869 \\
\hline Free $\mathrm{SO}_{2}$ & $2.84 \times 10^{-6} * * *$ & $\begin{array}{l}0.0160 \\
*\end{array}$ & 0.1258 & 0.0552 & 0.1980 & 0.4018 \\
\hline Total $\mathrm{SO}_{2}$ & $1.84 \times 10^{-10} * * *$ & $\begin{array}{l}0.0078 \\
* *\end{array}$ & 0.2924 & $\begin{array}{l}0.0119 \\
*\end{array}$ & 0.1032 & 0.2102 \\
\hline \% Cork weight loss & 0.6811 & $\begin{array}{l}0.0243 \\
*\end{array}$ & 0.1252 & 0.1314 & 0.2210 & 0.3230 \\
\hline
\end{tabular}

***99.9\% CI; **99\% CI; *95\% CI; .90\% CI.

month storage time. Free sulfur measurements after eight months of storage displayed significantly lower free sulfur in the LM and DM variants, once again likely due to the accelerated movement of oxygen from the headspace into the wine. In general, after one month there are some trends which support the anticipated result of separation between Control Program wines and Linear and/or Diurnal Program wines. However, there was not significant evidence to indicate that there was a difference between wines which were moved vs not moved within the same program. All other treatments were not significantly different. The colour analysis of the 12 wine treatments-shown in Figs. 6 to 8-indicated that there was a slightly higher colour intensity in all of the treated wines (CM, LNM, LM, DNM, and DM) in comparison to the Control Non-Movement wine. It appears after eight months, that movement of the wines is associated with the increase in browning in the control movement wine. This could be associated with the accelerated movement of oxygen from the headspace into the wine as was seen in the oxygen measurements. No significant difference was seen between the sulfur dioxide measurements for the CNM and CM variants. The other variants follow similar patterns as what was seen after one month storage.

The results of the triangle tests performed by the panel of judges are presented in Tables 3-6. Not many significant differences between the wines were revealed after one month. When evaluating the Scheurebe wines, the judges were able to distinguish the difference between the DM wine and the CNM wine, however no significant differences were found in the eight month tasting. For the Müller-Thurgau wines, the judges were not able to detect the difference 
Table 3 Scheurebe one month triangle test results.

\begin{tabular}{llll}
\hline Test & $\begin{array}{l}\text { Answers } \\
\text { taken }\end{array}$ & $\begin{array}{l}\text { Answers } \\
\text { right }\end{array}$ & Significance \\
\hline CNM vs CM & 13 & 6 & 0.2413 \\
CNM vs LNM & 13 & 4 & 0.6776 \\
CNM vs LM & 13 & 3 & 0.8613 \\
CNM vs DNM & 13 & 6 & 0.2413 \\
CNM vs DM & 13 & 8 & $0.0347^{*}$ \\
LNM vs DNM & 13 & 5 & 0.4480 \\
LM vs DM & 13 & 5 & 0.4480 \\
LNM vs LM & 13 & 3 & 0.8613 \\
DNM vs DM & 13 & 3 & 0.8613 \\
\hline
\end{tabular}

* 95\% CI.

Table 4 Müller-Thurgau one month triangle test results.

\begin{tabular}{llll}
\hline Test & $\begin{array}{l}\text { Answers } \\
\text { taken }\end{array}$ & $\begin{array}{l}\text { Answers } \\
\text { right }\end{array}$ & Significance \\
\hline CNM vs. CM & 14 & 4 & 0.7388 \\
CNM vs. LNM & 14 & 4 & 0.7388 \\
CNM vs. LM & 14 & 5 & 0.5245 \\
CNM vs. DNM & 14 & 5 & 0.5245 \\
CNM vs. DM & 14 & 3 & 0.8947 \\
LNM vs. DNM & 14 & 6 & 0.3102 \\
LM vs. DM & 14 & 7 & 0.1495 \\
LNM vs. LM & 14 & 5 & 0.5245 \\
DNM vs. DM & 14 & 8 & 0.0576 \\
Cork-In vs. Cork-Out Linear & 14 & 6 & 0.3102 \\
Cork-In vs. Cork-Out Diurnal & 14 & 3 & 0.8947 \\
\hline
\end{tabular}

* 95\% CI.

Table 5 Scheurebe eight month triangle test results.

\begin{tabular}{llll}
\hline Test & $\begin{array}{l}\text { Answers } \\
\text { taken }\end{array}$ & $\begin{array}{l}\text { Answers } \\
\text { right }\end{array}$ & Significance \\
\hline CNM vs. CM & 14 & 5 & 0.5245 \\
CNM vs. LNM & 14 & 4 & 0.7388 \\
CNM vs. LM & 14 & 4 & 0.7388 \\
CNM vs. DNM & 14 & 5 & 0.5245 \\
CNM vs. DM & 14 & 3 & 0.8947 \\
LNM vs. DNM & 14 & 4 & 0.7388 \\
LM vs. DM & 14 & 6 & 0.3102 \\
LNM vs. LM & 14 & 6 & 0.3102 \\
DNM vs. DM & 14 & 6 & 0.3102 \\
\hline Table 6 Müller-Thurgau eight month triangle test results. & & \\
\hline Test & Answers & Answers & Significance \\
\hline CNM vs. CM & taken & right & 0.1221 \\
CNM vs. LNM & 11 & 6 & $>0.9999$ \\
CNM vs. LM & 11 & 0 & 0.1221 \\
CNM vs. DNM & 11 & 6 & $0.0386^{*}$ \\
CNM vs. DM & 11 & 7 & $0.0088^{*}$ \\
LNM vs. DNM & 11 & 8 & $0.0386^{*}$ \\
LM vs. DM & 11 & 7 & 0.7659 \\
LNM vs. LM & 11 & 3 & 0.2890 \\
DNM vs. DM & 11 & 5 & $0.0088^{*}$ \\
\hline
\end{tabular}

*95\% CI. 
between any of the treatments when compared to the CNM wine or when comparing movement vs. non-movement wines within the same treatment for the first time point. The triangle tests showed significant differences for the Müller Thurgau after eight months of storage, mostly in comparison with the DNM treatment. Differences between the DM and the CNM were also noted. The descriptive analysis of the wines performed by 13 trained judges revealed a distinction between the Scheurebe and Müller-Thurgau wines. However, differences among wines within the same variety which were subjected to different treatments were not distinguishable using this method.

\section{Discussion}

These programs were designed to simulate different phases of the transport of wine in trans-equatorial conditions and to observe if a difference exists between a diurnal fluctuation of temperature (pumping effect) and a linear increase of temperature, both of which may be experienced in transport. Care was taken that both programs exerted the same amount of thermal energy on the wines. The pressure readings shown in Fig. 2 demonstrate that if the temperature is held steady, there is no increase in pressure in the bottles even if they are moved. Fig. 3 indicates that as the temperature increased, the pressure in the bottles also increased; specifically Day 1 and Day 6 of the Linear Increase program, there was an average temperature increase of $28{ }^{\circ} \mathrm{C}$ and a corresponding average pressure increase of 1.16 bar, or an increase of 0.04 bar per Celsius degree. This certainly agrees with literature, where previous reports have indicated that there is an expansion of liquid in the bottle with increasing temperatures [3]. It can also be seen the loss of pressure due to the expulsion of the corks later in the heating program. The movement of the bottles then had an impact on the average pressure. The Diurnal program created a higher rate of pressure increase, with the pressure increasing at a rate of 0.08 bar per ${ }^{\circ} \mathrm{C}$ overall. This is a larger pressure change than observed in the Linear Increase program, which indicates that the changes in pressure are more extreme in an environment where the temperatures are diurnally fluctuating. This is supported by previous research, which has shown that the changes in pressure are extreme during fluctuating temperatures due to "diurnal pumping" [4]. It is also noted that the movement does have an impact on the average pressure in the cooler part of the cycle which was when the bottles were shaken.

The oxygen levels within the wine bottles were also monitored throughout this experiment. It was shown in the Control Non-movement program that wines that were not exposed to increased temperature or movement showed a steadily decreasing level of oxygen in the headspace. This trend was accompanied by a corresponding increase in the oxygen level in the wine. This agrees with the literature, where it has been shown that the oxygen present in the headspace is taken up by the wine [10]. In the Control Movement program, it was observed that the movement of the wine caused a faster uptake of oxygen in the wine. There were higher final levels of oxygen within the wines in the CM program than the CNM program which can be attributed to the movement of the bottles. The shaking is allowing for faster incorporation of the headspace oxygen into the wine, resulting in higher wine oxygen levels in the Control Movement bottles than the Control Non-movement bottles by the end of the program. In both the Linear and Diurnal programs, it was observed that there was a decrease in oxygen in the wine as the temperature increased. This can be attributed to the fact that at warmer temperatures, the amount of oxygen which can physically be dissolved in wine decreases [13]. The trend of increased oxygen uptake in the wine when the bottles were subjected to movement was reinforced in both the LM and DM programs.

The chemical analysis of the wines revealed that there was a statistically significant difference between 
the Scheurebe and Müller-Thurgau wines related to density, alcohol, extracts, sugars, total acidity, specific acids, glycerin and sulfur dioxide levels, according to the Analysis of Variance performed on the measurements. This is the expected result, since the grape variety has a large impact on the overall matrix of a wine, and it is expected that wines made from different grape varieties will have different chemical parameters [14]. The variety did not have an impact on the $\mathrm{pH}$ or tartaric acid levels between the wines, which can be explained by the fact that both white wines came from the same region in Germany, where the $\mathrm{pH}$ is expected to be fairly high due to a relatively short growing season [14]. The variety also did not have an impact on the cork weight loss when the corks were dried, which can be perhaps attributed to the fact that the corks were of similar quality in both types of wine or to the short period of time which lapsed before the measurements were made. After eight months, variety did in fact have an impact on the cork weight loss measurements. The mean for the Scheurebe corks displayed a significantly greater average weight loss than the Müller-Thurgau. This can be explained in the fact that the corks remained intact and were subjected to greater wine saturation during the heat treatments than the Müller-Thurgau, which experienced drying in the temperature cabinet during the time when they were expelled. The ANOVA also revealed that the individual temperature and movement treatments had a statistically significant impact on the density, extract, sugar free extract, glycerin, tartaric acid, free sulfur dioxide, total sulfur dioxide and percent cork weight loss measurements. This is the expected result, indicating that bottles from the same treatment had the same chemical analysis and that bottle variation was not important enough to cause a statistically significant difference. In general, there are some trends which support the anticipated result of separation between Control Program wines and Linear and/or Diurnal Program wines. However, there was not significant evidence to indicate that there was a difference between wines which were moved vs not moved within the same program. Since several chemical and physical parameters changed when the wines underwent the treatments, these temperature and movement treatments had a significant impact on the wines matrix. A change in the wine matrix indicates that sensory parameters may have also been influenced, causing changes to the wine's perceived quality.

The colour analysis of the 12 wine treatments indicated that there was a slightly higher colour intensity in all of the treated wines (CM, LNM, LM, DNM, and DM) in comparison to the Control Non-Movement wine (Figs. 6-8). It can be seen in these figures that the LNM, LM, DNM and DM wines have a higher intensity in the $380-530 \mathrm{~nm}$ range than the CNM wines, indicating an increased intensity in the yellow-brown visible range. This was the anticipated result, since the movement of the bottles is expected to introduce oxygen into the wine, and increased levels of oxygen in the wine have been shown to have an impact on wine colour, specifically via browning [1]. These results are expected to become more obvious as the wines age and undergo further browning.

Through the triangle tests performed by the panel of judges, not many significant differences between the wines were revealed. For the Müller-Thurgau wines, the judges were not able to detect the difference among any of the treatments when compared to the CNM wine or when comparing movement vs non-movement wines within the same treatment, which does not agree with previous studies. However, when evaluating the Scheurebe wines, the judges were able to distinguish the difference between the Diurnal Movement wine and the CNM wine. This is an expected result, since it has previously been shown that wines which are submitted to transportation conditions, including diurnally fluctuating temperatures and movement, undergo sensorial changes [4]. After eight months of storage in cellar conditions $\left(17^{\circ} \mathrm{C}\right)$, the 

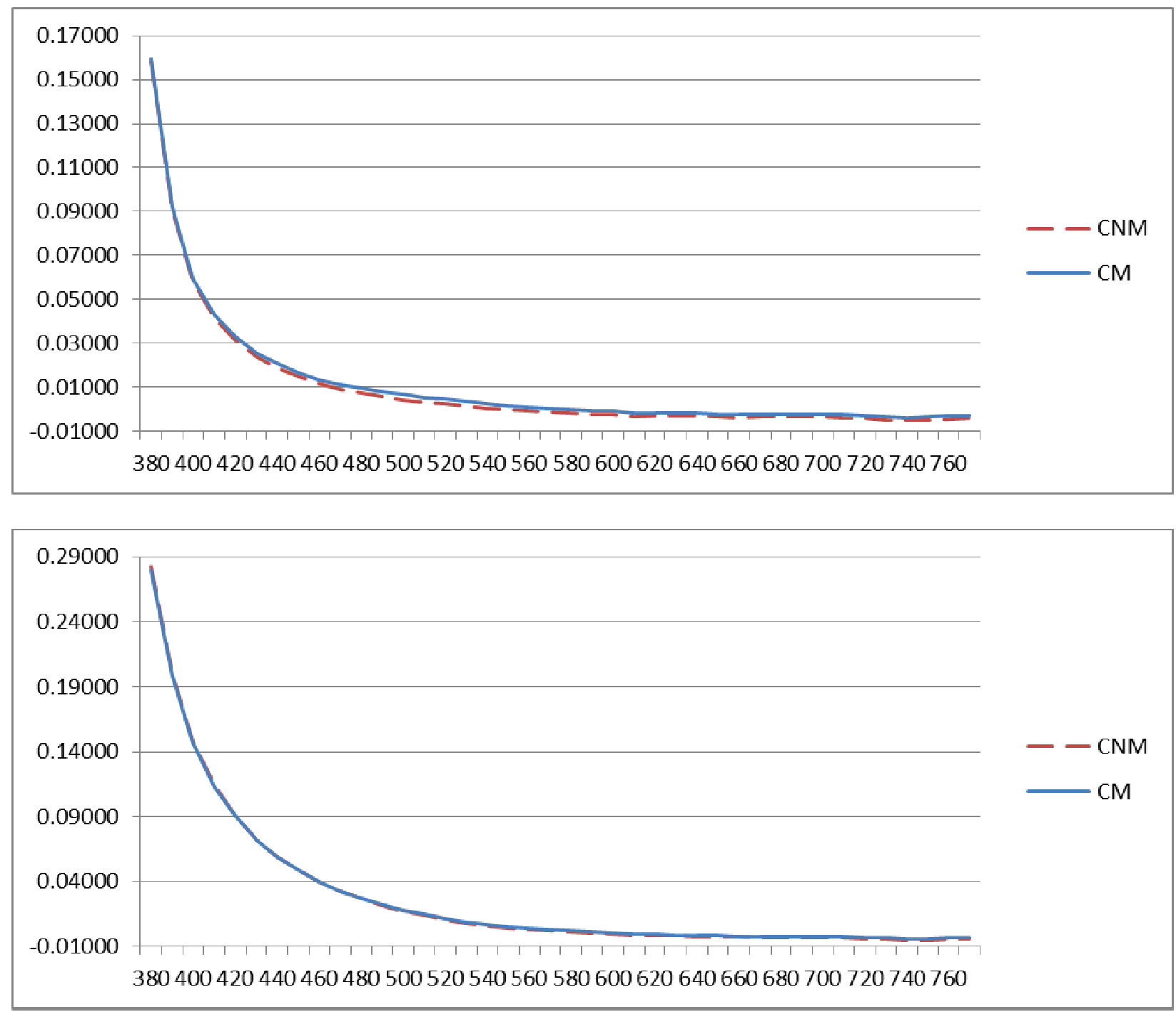

Fig. 6 Control program spectrophotometry results for Müller-Thurgau (top) and scheurebe (bottom).

repeat of the difference tests again showed no significant differences among treatments in the Scheurebe wines. It was expected that all of the treated wines would be sensorially different from the CNM wine, but this was not the case. The Müller-Thurgau wines which were stored for an additional eight months showed more differences than those tasted after only one month. The expert panelists found significant differences between the DNM treatment and CNM, DM, and LNM treatments, as well as between the DM and CNM treatments. During the simulated temperature treatments, the DNM and DM Müller-Thurgau wines experienced corks pushing and corks expelling out of the bottles due to the pressure change and pumping. This problem was resolved by re-corking the wines and adjusting the temperature program to lower temperatures, and extending the program to maintain the same thermal energy exertion. The same was not observed with the Scheurebe wines. This could be due to the amount of time the corks had spent in the bottle or the concentration of $\mathrm{CO}_{2}$ in the wine, as the Müller-Thurgau was bottled shortly before the experiment began. The differences found in the diurnally treated Müller-Thurgau wines could be a result of the cork expulsion early in the program and the replaced corks being drier than those which remained intact and therefore not having a proper seal. 

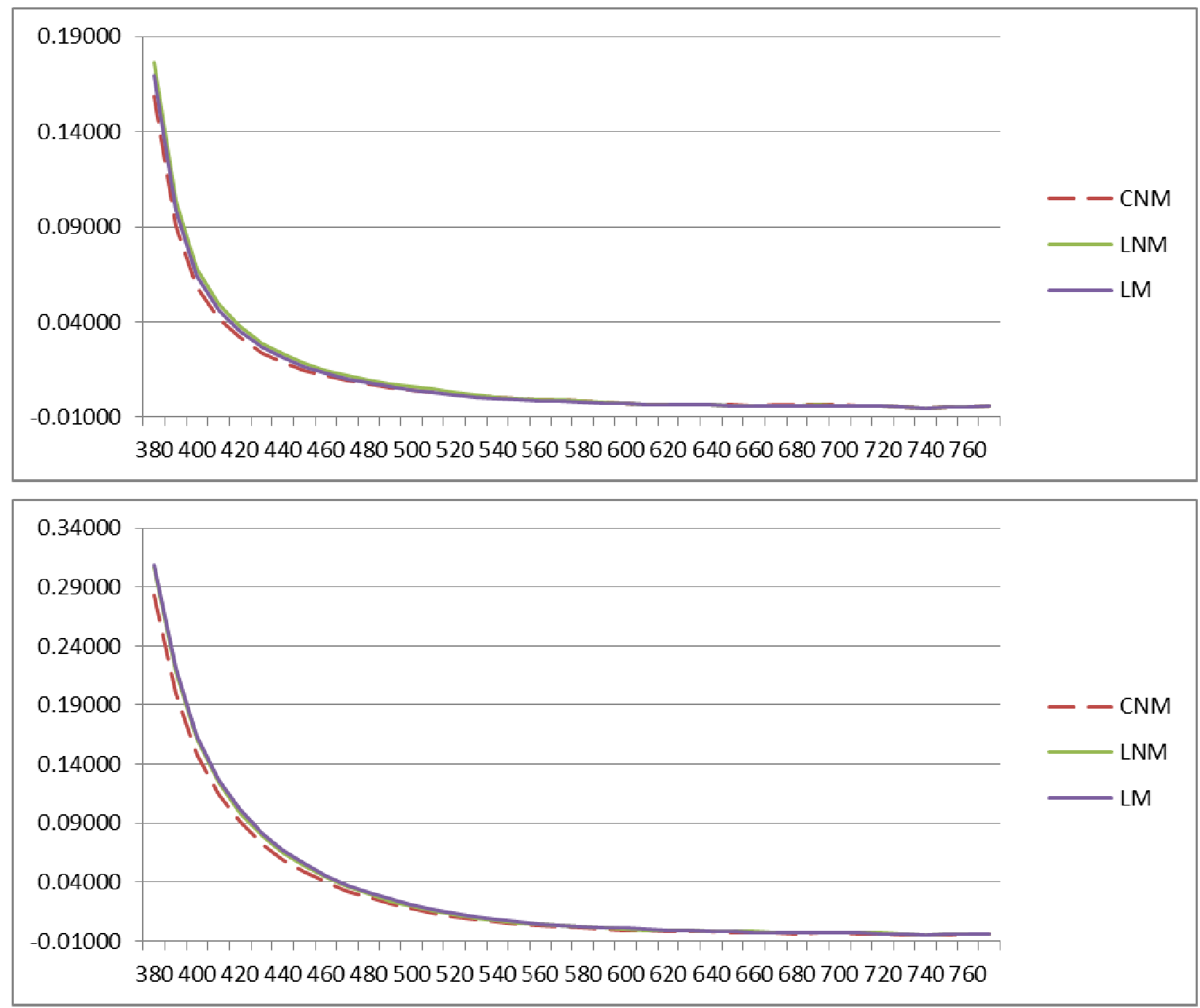

Fig. 7 Linear program spectrophotometry results for Müller-Thurgau (top) and scheurebe (bottom).

Another possible explanation for the significant differences detected for the diurnal Müller-Thurgau wines is over the course of eight months and through accelerated aging of the temperature treatments, that the wines lost some of the primary fruity aromas commonly associated with freshly bottled white wines.

The descriptive analysis of the wines performed by 13 trained judges revealed a distinction between the Scheurebe and Müller-Thurgau wines. Nine out of the 13 attributes agreed upon by the panel described the differences between the wines in a statistically significant way, which indicates that the panel appropriately streamlined and utilized the list of attributes. The aroma intensity, acidity, sweetness and bitterness attributes are not well separated in Fig. 9. The fact that all the wines are dry white wines coming from a cool climate region explains the result that all the wines have similar values for acidity, sweetness, bitterness and aroma intensity. It is also not surprising that the temperature and movement treatments did not make a significant impact on the wines for these attributes, as they have been found to be relatively stable even under temperature changes and oxygen exposure [14]. Fig. 9 indicates that the wines were easily separated by variety according to the remaining attributes, however, differences among wines within the same variety which were subjected to different 

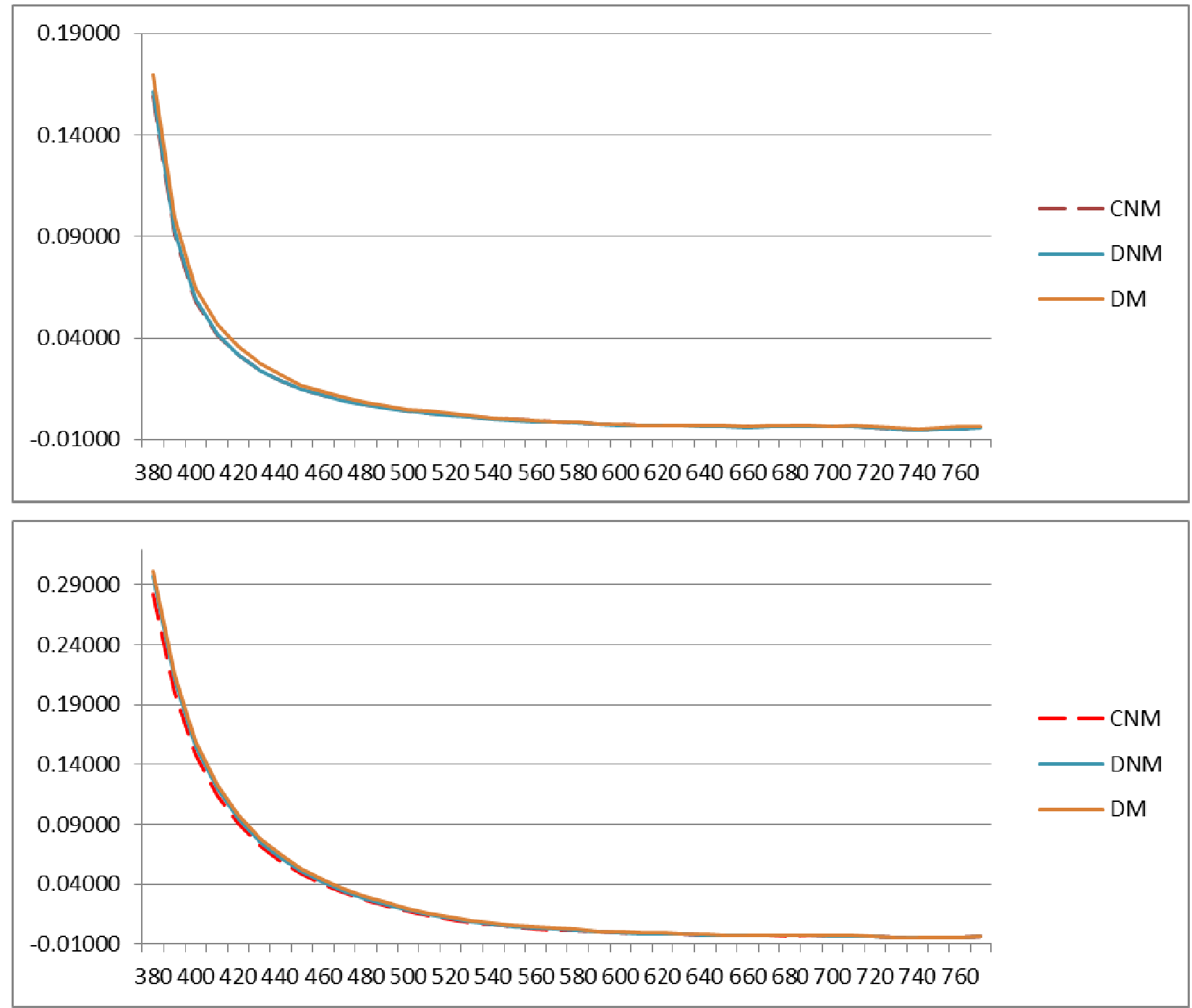

Fig. 8 Diurnal program spectrophotometry results for Müller-Thurgau (top) and scheurebe (bottom).

treatments were not distinguishable through descriptive analysis. This indicates that subjecting wines to simulated transportation conditions does not have a significant impact on the sensory qualities of these wines, especially when evaluated shortly after the simulated transportation. It would be expected that wines submitted to higher temperatures in the Linear and Diurnal programs would be rated higher for attributes such as Burnt Aroma and Oxidized Aroma, and lower for fruit aromas [11]. In other research, the temperature programs or the duration of actual transport lasted longer than the program described in this paper. This may account for the results differing from those found in previous research.
The Principal Component Analysis displayed in Fig. 10 accounts for $92.9 \%$ of the variance within the data set. This means that this PCA displays the relationships between the data with only $7.1 \%$ of the variance in the data unaccounted for, which indicates this PCA is highly accurate [12]. It can be seen that PC1 is highly correlated with all of the aroma descriptors. The Stone Fruit, Citrus Fruit, Tropical Fruit and Candy attributes fall in the positive direction of the x-axis, and are therefore positively correlated with PC1. The Vegetable, Oxidized, Honey/Marzipan, Earthy/Moldy and Burnt Aroma attributes lie in the negative direction of the $\mathrm{x}$-axis, and are negatively correlated with PC1 and with the other attributes. There 


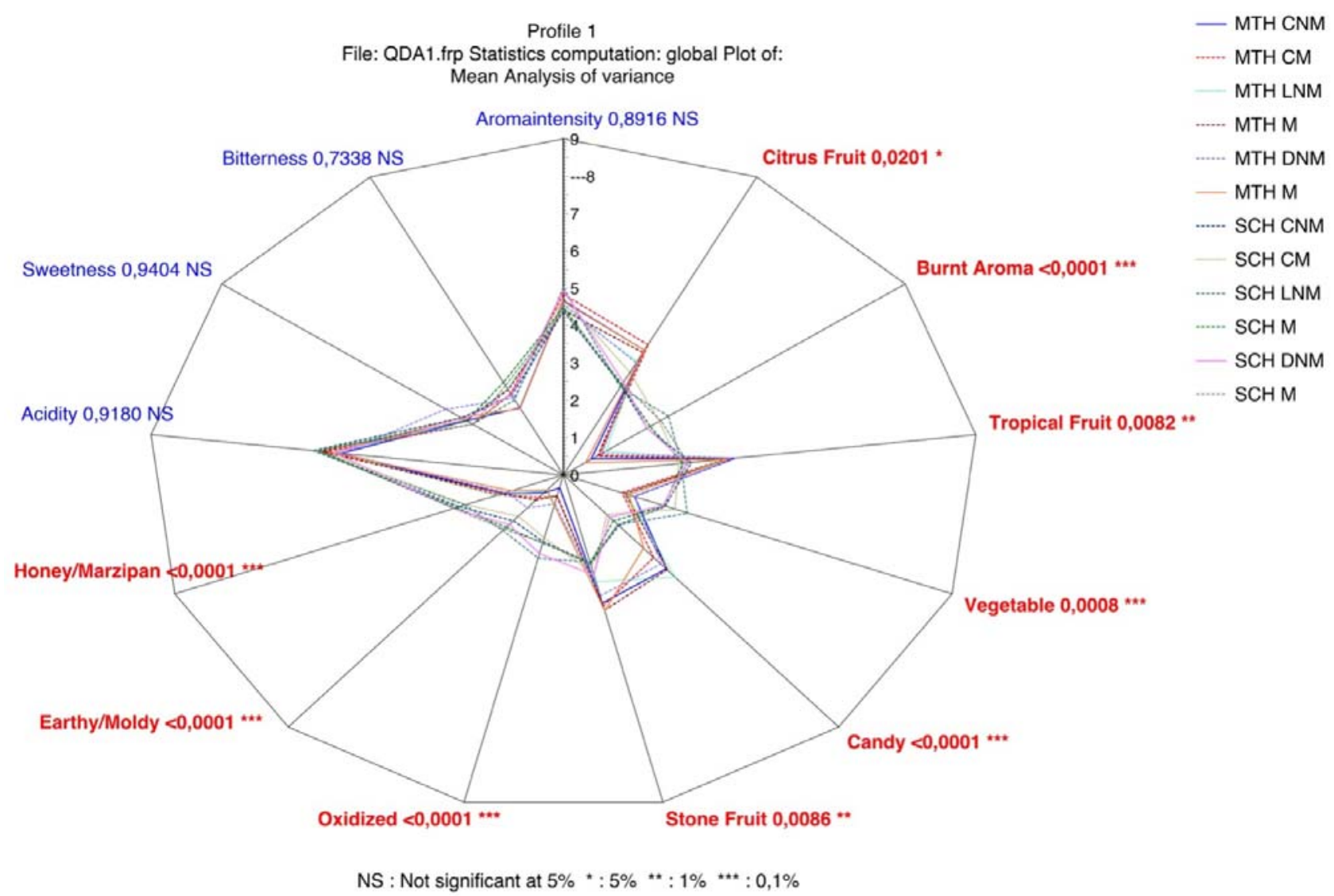

Fig. 9 Spider plot of mean analysis of variance from descriptive analysis.

is almost a direct negative correlation between the Tropical Fruit and Vegetable attributes, which indicates that a wine which was rated highly for Tropical Fruit was simultaneously rated at a low value for the Vegetable attribute, and vice versa. Burnt Aroma, Earthy/Moldy and Honey/Marzipan attributes placed quite close to each other on this PCA, which indicates that when one of these attributes were rated at a high intensity, the other attributes were also rated highly. Similar groups with high positive correlation include the Vegetable and Oxidized attributes, and the Stone Fruit and Citrus Fruit attributes. It is the expected result that the various Fruit attributes would be positively correlated to each other, since fruity aromas can often be from similar chemical compounds (esters) which are present at the same time in wines [15]. Furthermore, Robinson (2010) showed that there was a negative correlation between tropical fruit and rubber aromas in their study of the impact of simulated transportation conditions on the sensory profile of Riesling wines. This finding is echoed here, as Fig. 10 shows that Tropical Fruit is in the positive direction of PC1 and Burnt Aroma- which included burnt rubber- is in the negative direction of PC1. It was also demonstrated in the previous study that the attributes of citrus fruit and vegetable/oxidation were negatively correlated, which is a trend seen in the Principal Component Analysis generated in this experiment as well [11].

Fig. 11 depicts the PCA with each of the wine treatments transposed on the graph, revealing the correlation between each of the experimental treatments and the vectors of the descriptors on the PCA circle graph. It can be seen that there is a clear separation between the varieties on this PCA graph. The Scheurebe wines are highly correlated with 


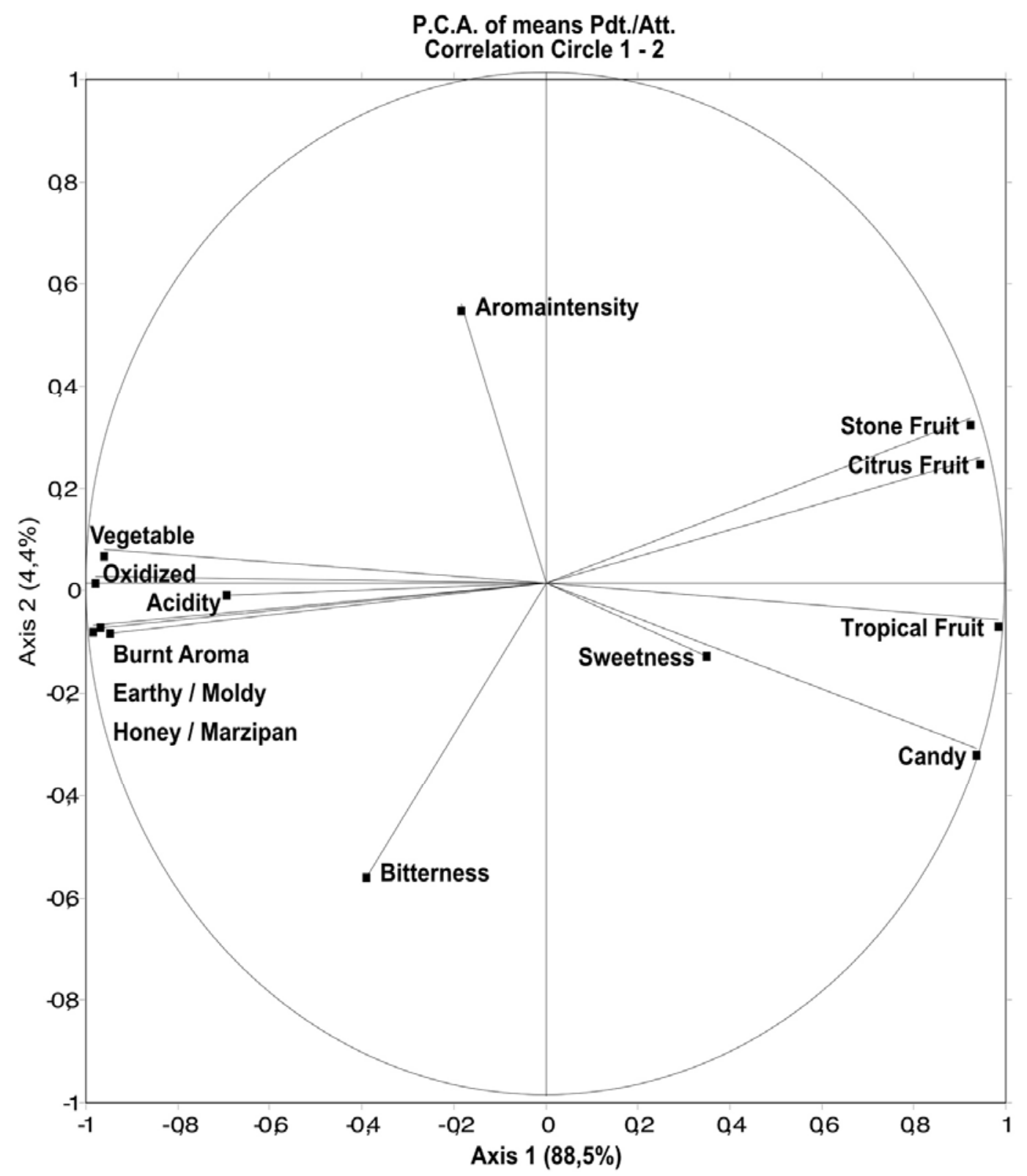

Fig. 10 Principal component analysis of descriptive analysis attributes.

the negative side of PC1, and therefore are also highly correlated with the attributes in the negative $x$ direction. Fig. 11 also reveals that the Müller-Thurgau wines are highly correlated with the positive quadrants of PC1 and strong in Stone Fruit, Citrus Fruit, Tropical Fruit and Candy attributes, and negatively correlated with the Vegetable, Oxidized, Honey/Marzipan, Earthy/Moldy and Burnt aromas. The separation of the two varieties through sensorial analysis was expected however, it was predicted that there would also be separation of the wines according to experimental treatment, based on the fact that simulated transportation conditions have been shown to impact the sensory profiles of wines [11]. It was expected, based on previous work, that the wines associated with higher temperatures would be associated with oxidized and rubber aromas, while wines kept at low temperatures would maintain their citrus, floral and tropical fruit aromas. It was also anticipated that wines subjected to movement would 
P.C.A. of means Product / Attribute

Plan 1-2 BiPlot constant: 10,0

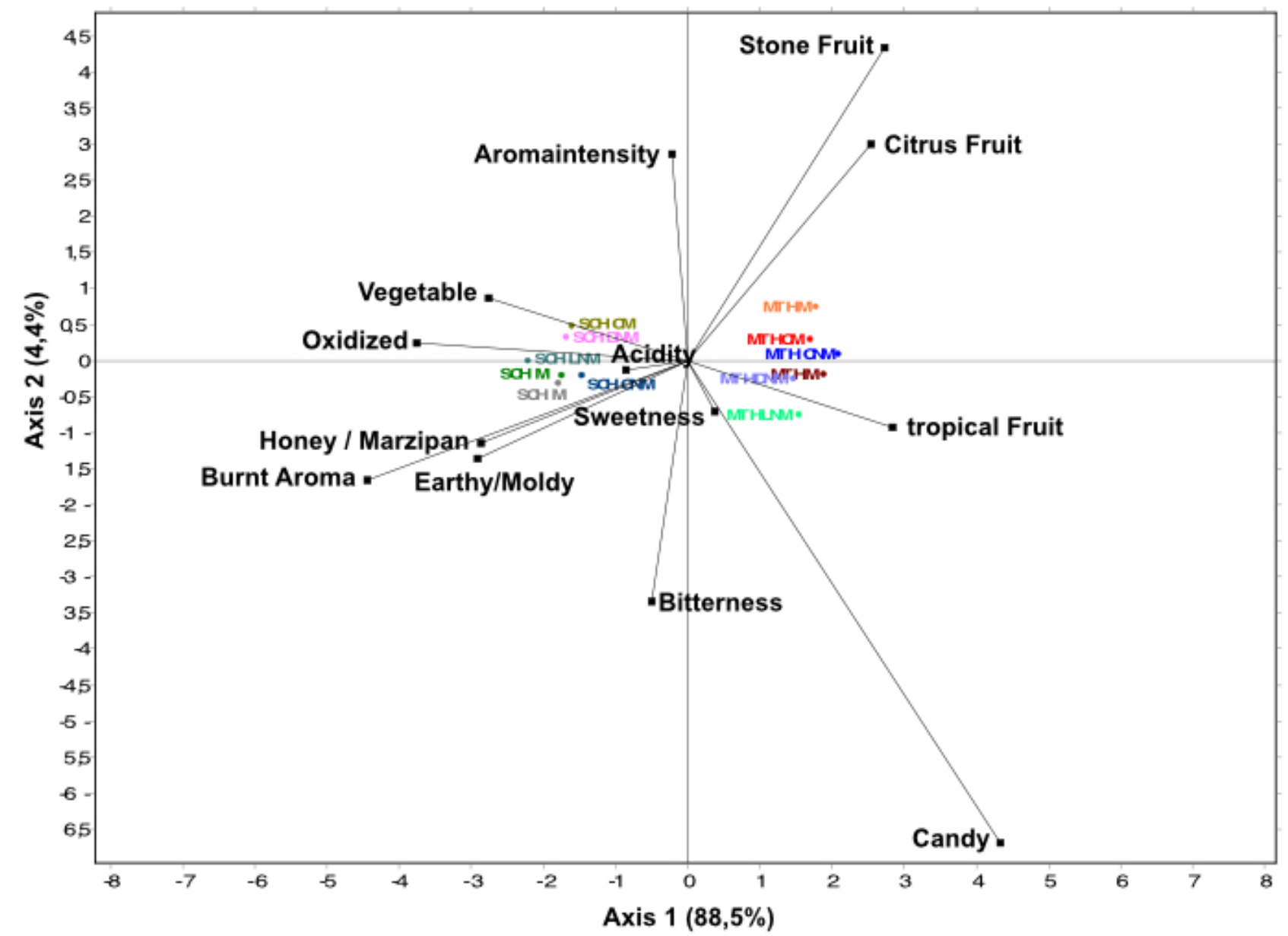

Fig. 11 Principal component analysis of descriptive analysis attributes with wine treatments.

have a higher oxygen level in the wine, and would therefore also reveal more oxidized aromas and decreased fruit aromas. Additionally, wines that were subjected to the diurnal fluctuations of temperature were expected to show higher oxygen levels than the linear treatment due to the pumping effect caused by thermal expansion and retraction. Comparing the experimental treatments to the Control Non-Movement wine, these predicted trends were not realized in this project. These differences in results could be due to the differences in temperature programs, the length of time the wines were exposed to high temperatures, or a result of the wines chosen for this project. This research found that the wines were more robust than expected. There were slight chemical and physical changes to the treated wines, however, the sensory profiles of young white wines were robust to transportation conditions, especially shortly after the experiment. Those sensorial differences which were found among the Müller-Thurgau wines are suggested to be associated with the expulsion of the corks during the heat treatments. This is a positive result for much of the international wine industry, particularly for those wineries which ship wine domestically and internationally. As future research, the wines should be re-evaluated after some time has passed in order to observe if these trends reveal themselves with 
increased age of the wines.

\section{Conclusion}

The 12 treatments showed differences amongst themselves when evaluated for colour intensity, density, extract, sugar free extract, glycerin, tartaric acid, free sulfur dioxide, total sulfur dioxide and percent cork weight loss. One month after the simulated transport conditions, the triangle tests revealed that there was a sensorial difference between the DM Scheurebe wine and the control. However, this result was not repeated when the wines were re-evaluated after eight months storage. The Müller-Thurgau wines showed differences associated with the DNM treatment in triangle tests after eight months of cellaring which may be associated with the corks being expelled and recorked early in the temperature program. The DA panel showed that the wines could only be differentiated according to variety, rather than experimental treatment. This indicates that the simulated transportation conditions did not have a significant sensorial impact on the wines. For an industry where young white wines are regularly subjected to shipping conditions like the ones simulated in this project, this is a benefit. It has been shown that while there are slight chemical and physical changes to the wines during shipping, the sensory profiles of young white wines are robust to transportations conditions, especially if consumed within a short period of time. Pressure change correlated with the temperature program: Linear +0.04 bar $/{ }^{\circ} \mathrm{C}$, Diurnal +0.08 bar $/{ }^{\circ} \mathrm{C}$. Patterns of oxygen uptake differed among the treatments, as the movement of the bottles caused a spike in the wine oxygen levels. Colour intensity increased in all treated wines compared to control. Future recommendations are to investigate these wines after more time has elapsed to see if the chemical changes in the wines eventually manifest as sensorial changes, and to investigate the impact of these simulated transportation conditions on other varieties and styles.

\section{References}

[1] Benitez, P., Castro, R., and Barroso, C. 2003. "Changes in the Polyphenolic and Volatile Contents of 'Fino' Sherry Wine Exposed to Ultraviolet and Visible Radiation during Storage.” Journal of Agricultural and Food Chemistry 51: 6482-7.

[2] Hartley, A. 2008. Bulk Shipping of Wine and Its Implications for Product Quality. Australian Wine Research Institute, 1-19.

[3] Meyer, M. 2002. Final Report-A Study of the Impact of Shipping/Transportation Conditions and Practices on Wine. Australian Wine Research Institute, 1-42.

[4] MacCawley, A. 2014. The International Wine Supply Chain: Challenges from Bottling to the Glass. Atlanta: Georgia Institute of Technology.

[5] Butzke, C., Vogtn, E., and Chacon-Rodriguez, L. 2012. "Effects of Heat Exposure on Wine Quality during Transport and Storage." Journal of Wine Research 23: 15-25.

[6] Chonhenchob, V., Sittipod, S., Swasdee, D., Rachtanapun, P., Singh, S., and Singh, J. 2009. "Effect of Truck Vibration during Transport on Damage to Fresh Produce Shipments in Thailand.” Journal of Applied Packaging Research 3: 27-39.

[7] Chung, H., Son, J., Park, E., Kim, E., and Lim, S. 2008. "Effect of Vibration and Storage on Some Physio-Chemical Properties of a Commercial Red Wine.” Journal of Food Composition and Analysis 2: 655-9.

[8] Doyon, G., Clement, A. S., Ribereau, S., and Morin, G. 2005. "Canadian Bag-in-Box Wine under Distribution Channel Abuse: Material Fatigue, Flexing Simulation and Total Closure/Spout Leakage Investigation.” Packaging Technology and Science18 (2): 97-106.

[9] Jung, R., Lehy, B., Patz, C., Rothermel, A., and Schuessler, C. 2014. "Potential Wine Ageing during Transportation.” In 37th OIV Congress. Argentina: Organisation Internationale de la Vigneet du Vin, 1-6.

[10] Jung, R., Freund, M., Schussler, C., and Seckler, J. 2009. "Impact of Oxygen Level in Wine at Bottling." Practical Winery and Vineyard Journal: 1-3.

[11] Robinson, A. 2010. "Effect of Simulated Shipping Conditions on Sensory Attribute and Volatile Composition of Commercial White and Red Wines." American Journal of Enology and Viticulture : 337-47.

[12] Lawless, H., and Heymann, H. 1998. Sensory Evaluation of Food: Principles and Practices. New York: Chapman and Hall.

[13] Muller-Spath, H. 1984. "Transporting Wine with or without Inert Gas.” In International Wine Transportation Symposium. Montreal, Canada: Seitz, 16-9. 

Sensory Profiles of Müller-Thurgau and Scheurebe Wines

[14] Boulton, R., Singleton, V., Bisson, L., and Kunkee, R. 1996. Principles and Practices of Winemaking. London: Chapmann \& Hall.
[15] D’Auria, M., Emanuele, L., and Racioppo, R. 2009. “The Effect of Heat and Light on the Composition of Some Volatile Compounds in Wine.” Food Chemistry, 9-14. 